\title{
Last rites
}

\author{
Fiona Godlee editor, BMJ
}

The Liverpool care pathway was developed in the UK in the late 1990s. Since then it has been adopted at national level by 20 other countries, reflecting growing efforts around the world to improve care for patients dying in hospital. But last week the pathway was given its own last rites by the UK government, in response to an independent review (BMJ 2013;347:f4568)

In this week's journal, Krishna Chinthapalli tells the story of the LCP from its origins in the hospice movement to its UK demise. He asks where doctors, especially trainees, can now turn for necessary reminders to consider all aspects of a dying patient's care, and for specific guidance on symptom management (doi:10.1136/bmj.f4669). In an editorial, the pathway's architect, John Ellershaw, reiterates the underlying principles of good end of life care, calling for these to be applied wherever a person is dying: hospital, hospice, or home (doi:10. 1136/bmj.f4428).

Given the determined and at times sensationalist media campaign against the pathway (BMJ 2012;345:e7316), and the undisputed reports of appalling care experienced by patients dying under the LCP banner, the Neuberger review had no choice but to recommend that the pathway be phased out. Stories of patients being denied food and water, being left untended with inadequate pain and symptom relief, and being placed on the pathway without proper communication, had left the LCP as a brand too tarnished to be saved.

But the review made clear that, when properly implemented, the pathway improves care for patients at the end of life. What the LCP needed, it said, was better training for all staff, more support and supervision for trainees especially at night and at weekends, and better communication with patients, their families, and the public about death and dying as a normal part of life. The review also called for more research, since although the pathway represents current best practice, there is little good evidence to help us decide which approaches are really best under which circumstances.

In their editorial, Ellershaw and Mayur Lakhani list the 10 key elements of good care for the dying patient, covering good communication, spiritual care, and anticipatory prescribing for symptom relief. But of them all, perhaps the most important is the very first: recognition that the patient is dying. All else flows from this, yet it remains something that doctors seem most challenged and troubled by.

The scrapping of the LCP in the UK is a serious failure not of ideas but of implementation. At fault was a lack of training, staffing, support, common sense, and humanity. It is these problems that we must fight against in today's NHS. The principles of the pathway remain sound. Amidst the UK's current retreat we must not lose sight of them, since the need for their widespread application has never been greater. And if and when personalised end of life care plans emerge from the LCP's ashes, let's just call them that.

Cite this as: BMJ 2013;347:f4714

๑ BMJ Publishing Group Ltd 2013 